\title{
GARNET SINGLE CRYSTAL AS SUBSTRATE MATERIAL FOR HTSC FILMS
}

\author{
P. Mukhopadhyay \\ Advanced Centre for Research in Electronics, Indian Institute of Technology \\ Powai, Bombay-400076, India
}

The use of high temperature superconductor for device application has made the compatibility of the film and substrate an important issue. Garnets having reasonably low dielectric constant and low dielectric losses can be viable low cost substrate materials for the microwave devices. Garnet single crystals like $\mathrm{Gd}_{3} \mathrm{Ga}_{5} \mathrm{O}_{12}$ (GGG), $\mathrm{Y}_{3} \mathrm{Ga}_{5} \mathrm{O}_{12}$ (YGG), $\mathrm{Y}_{3} \mathrm{Al}_{5} \mathrm{O}_{12}$ (YAG) etc. can be potential HTSC substrate materials for microwave devices. Properties of HTSC films on some of these garnet crystals are compared here.

PACS numbers: 68.55.-a, 68.60.-p, 74.76.Bz, 81.15.-z

\section{Viable substrates for HTSC microwave quality films}

Most device applications require substrates which are non-expensive, non-fragile, easily available in large size, free of structural inhomogeneities and phase transitions, chemically stable at the interface, flat, defect-free, having good thermal expansion and lattice match with the HTSC films. For high frequency micromillimeter wave devices the substrate should also satisfy the criteria of low dielectric constant $(\varepsilon<20)$, low loss tangent $\left(\tan \delta<10^{-3}\right)$ and have isotropic microwave properties. Such requirements are not met uniformly by various available substrates and make the search for viable substrates an open and active area of research.

Rare-earth alluminates [1], gallates [2,3] and orthoferrites [4, 5] are materials having excellent microwave properties and have been tried to grow good epitaxial $\mathrm{YBa}_{2} \mathrm{Cu}_{3} \mathrm{O}_{7-x}$ (YBCO) films. All these substrate materials, however, suffer from the major drawback of undergoing structural phase transformation leading to twinning causing undesirable strains in the ITSC films [6]. Sapphire $\left(\mathrm{Al}_{2} \mathrm{O}_{3}\right)$, also a good microwave substrate, is a low cost material but suffers from anisotropic dielectric properties and reactivity with $\mathrm{YBCO}$ film. Tetragonal $\mathrm{ABCO}_{4}$ single crystals $(\mathrm{A}=\mathrm{Sr}, \mathrm{Ca} ; \mathrm{B}=$ rare-earth element and $\mathrm{C}=\mathrm{Ga}$ or $\mathrm{Al}$ ) have also been found suitable to grow epitaxial films of $\mathrm{YBCO}$ and $\mathrm{Bi}-\mathrm{Sr}-\mathrm{Ca}-\mathrm{Cu}-\mathrm{O}$ (BSCCO) and have low dielectric constants [7]. From this perovskite aluminate group $\mathrm{CaNdAlO}_{4}$ are better microwave substrates than $\mathrm{SrLaAlO}_{4}$ crystals which are extremely brittle. Another family of substrate materials having low dielectric constants $(<20)$ and 
low loss tangents $\left(<10^{-3}\right)$ are spinels and garnets. We demonstrated and reported for the first time the use of gadolinium gallium garnet $\left(\mathrm{Gd}_{3} \mathrm{Ga}_{5} \mathrm{O}_{12}\right)$ single crystal as a potential substrate for growing highly oriented thin films of YBCO $[8,9]$ and screen printed thick films of $\mathrm{Bi}-\mathrm{Sr}-\mathrm{Ca}-\mathrm{Cu}-\mathrm{O}$ (with the chemical composition $\mathrm{Bi}: \mathrm{Sr}: \mathrm{Ca}: \mathrm{Cu}=2: 2: 2: 3)$ superconductors [10]. Aluminium spinel $\left(\mathrm{MgAl}_{2} \mathrm{O}_{4}\right)$ substrates have also been used to grow both thick [11] and thin [12] films of YBCO but found to be reactive with HTSC films. $c$-axis oriented thin films of $\mathrm{Bi}-\mathrm{Sr}-\mathrm{Ca}-\mathrm{Cu}-\mathrm{O}$ $(2: 2: 2: 1)$ grown by MOCVD on yttrium aluminium garnet $\left(\mathrm{Y}_{3} \mathrm{Al}_{3} \mathrm{O}_{12}\right)$ have also been reported [13].

\section{Garnet substrates}

\subsection{Properties of rare-earth garnet substrates}

We shall consider the properties of rare-earth garnet substrates of the type $\mathrm{A}_{3} \mathrm{~B}_{5} \mathrm{O}_{12}$ (where $\mathrm{A}=\mathrm{Y}$ or rare-earth element, $\mathrm{B}=\mathrm{Fe}, \mathrm{Ga}$ or $\mathrm{Al}$ ) as a suitable material for growing HTSC microwave quality films.

Garnets can be viable substrates for growth of IITSC microwave quality films. High quality single crystals of rare-earth garnets with low defect structure $\left(<5 / \mathrm{mm}^{2}\right)$ can be grown by Czochralski method and relatively non-expensive substrate wafers of $8^{\prime \prime}$ diameter or more can easily be available commercially. The garnet substrates are mechanically strong (to $<0.010^{\prime \prime}$ ) and have properties suitable for growing HTSC microwave quality films. They have low loss tangent $\left(\tan \delta<10^{-3}-10^{-5}\right)$, low dielectric constant $(\varepsilon=9-14)$, chemical compatibility with HTSC films (with effective lattice mismatch $<3 \%$ ), thermal expansion coefficient in the range of $3.35-14 \times 10^{-6} \mathrm{~K}^{-1}$ and isotropic microwave properties.

\subsection{Properties of YBCO-IITSC films on garnet substrates}

Different oriented films can be easily grown on garnet substrates by choosing appropriate substrate orientation or a proper buffer material. We shall compare here the properties of YBCO thin films grown on gadolinium gallium garnet and yttrium aluminium garnet substrates grown by standard in situ laser ablation technique [8].

YBCO thin films of preferred $a$ - or $c$-axis orientation can be grown directly on (111)-oriented GGG substrates by depositing films at suitable substrate temperatures $\left(T_{\mathrm{s}}\right)$. At lower $T_{\mathrm{s}}$ mixed $a-c$ oriented films $\left(T_{\mathrm{s}} \approx 620-640^{\circ} \mathrm{C}\right)$ or preferred $a$-axis oriented films $\left(T_{\mathrm{s}} \approx 650-670^{\circ} \mathrm{C}\right)$ can be obtained. At higher substrate temperatures $\left(T_{\mathrm{s}}>700^{\circ} \mathrm{C}\right), c$-axis films can be grown on $(211) /(100) /(110)$ GGG [14] as well as on (001)YAG substrates. At $T_{\mathrm{s}}>700^{\circ} \mathrm{C}, c$-axis oriented films can also be obtained on garnet substrates with a suitable thin buffer layer of yttria stabilized zirconia (YSZ) or cerium oxide $\left(\mathrm{CeO}_{2}\right)$.

\section{Results and discussions}

The X-ray diffraction patterns of the YBCO films on (111)GGG substrate with a buffer of $1000 \AA$ of YSZ, (111)GGG and (001)YAG substrates are shown in Fig. 1c-e. Figure $1 \mathrm{a}$ and $1 \mathrm{~b}$ show the same for polycrystalline GGG and (111)GGG 


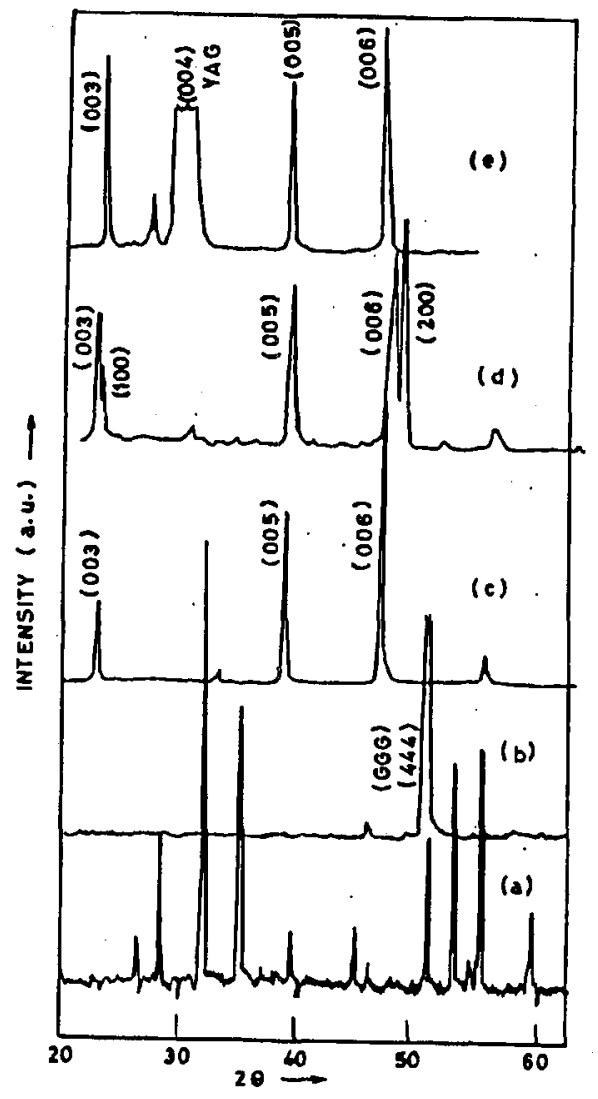

Fig. 1. XRD of (a) polycrystalline GGG, (b) (111)GGG substrate and XRD of YBCO film on (c) YSZ buffer/GGG, (d) (111)GGG and (e) (001)YAG.

substrate. Figure 1b of (111)GGG substrate shows the maximum intensity peak at an angle of $51.07^{\circ}$ corresponding to (444) plane. Diffraction peaks for the YBCO film on YSZ/GGG and YAG substrates correspond to $c$-axis oriented films with the maximum intensity peaks occurring at an angle $46.8^{\circ}$ and $46.9^{\circ}$ (Fig. 1c,e), while the peaks for the film on bare (111)GGG were a mixture of $a$-axis and $c$-axis oriented films with the maximum intensity peak occurring at an angle $47.5^{\circ}$ corresponding to an $a$-axis oriented film.

Figure 2 compares the resistance against temperature for the above mentioned YBCO films on (001)YAG (Fig. 2i), (111)GGG (Fig. 2ii) and YSZ buffered (111)GGG (Fig. 2iii). The $c$-axis oriented films both on YAG and YSZ/GGG show a lower zero resistance transition temperature $\left(T_{c}^{R=0}=87-88^{\circ} \mathrm{C}\right)$ compared to the transition temperature $\left(T_{\mathrm{c}}^{R=0}=90-92^{\circ} \mathrm{C}\right)$ for $a$-axis oriented film on (111)GGG. The room temperature resistance $R^{\text {R.T. }}$ [ohm] of the corresponding films (i), (ii) and (iii) was 5.3, 4 and 2.2. The stoichiometry of the films from energy dispersive X-ray spectrum (EDX) shows the c-oriented films to be $\mathrm{Cu}$-rich in comparison to the $a$-oriented films and the possibility of having both the $\mathrm{YBa}_{2} \mathrm{Cu}_{3} \mathrm{O}_{7-x}$ 


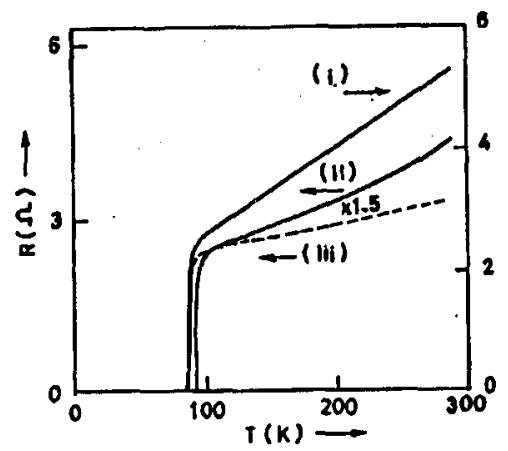

Fig. 2. Resistance against temperature of YBCO films on (i) (001)YAG, (ii) (111)GGG and (iii) YSZ buffer/GGG.

(123 phase $\mathrm{YBCO}$ ) and $\mathrm{Y}_{2} \mathrm{Ba}_{4} \mathrm{Cu}_{8} \mathrm{O}_{x}(124$ phase $\mathrm{YBCO}$ ) phases. The $124-\mathrm{YBCO}$ has a lower transition temperature $(80 . \mathrm{K})$ compared to pure $123-\mathrm{YBCO}$ of $90 \mathrm{~K}$ and mixture of the two phases present explains the lower $T_{\mathrm{c}}^{R=0}$ in the $c$-axis oriented films on garnets. The processing parameters and properties of laser deposited YBCO films on GGG and YAG substrates are summarized in Table.

TABLE

Comparison of processing parameters and properties of laser deposited YBCO films on GGG(111 and 211) and YAG (001) substrates.

\begin{tabular}{|c|c|c|c|}
\hline & GGG(111) & GGG(211) & YAG(001) \\
\hline \multicolumn{4}{|c|}{ Laser deposition parameters } \\
\hline O-partial pressure $[\mathrm{mTr}]$ & $100-200$ & 100 & 200 \\
\hline Laser density $\left[\mathrm{J} / \mathrm{cm}^{2}\right]$ & 2 & $1-2$ & 1.5 \\
\hline Laser repetition rate $[\mathrm{Hz}]$ & 5 & $5-10$ & 5 \\
\hline \multicolumn{4}{|l|}{ Substrate temperature } \\
\hline$\left[{ }^{\circ} \mathrm{C}\right]$ & $600-700$ & $740-800$ & 740 \\
\hline \multicolumn{4}{|c|}{ Properties of YBCO films } \\
\hline $\begin{array}{l}\text { Transition temperature } \\
T_{c}^{R=0}[\mathrm{~K}]\end{array}$ & $90-92$ & 87 & 87 \\
\hline Transition width $\Delta T[\mathrm{~K}]$ & $1-2$ & $2-3$ & $2-3$ \\
\hline Orientation & preffered $a$ or $c$-axis & $c$-axis & $c$-axis \\
\hline$J_{c}\left[\mathrm{~A} / \mathrm{cm}^{2}\right]$ at $77 \mathrm{~K}$ & $10^{4}$ & $10^{5}$ & $10^{5}$ \\
\hline Stoichiometry & Y-rich & $\mathrm{Cu}$-rich & Cu-rich \\
\hline Phase & $\mathrm{YBa}_{2} \mathrm{Cu}_{3} \mathrm{O}_{7-x}$ & $\mathrm{YBa}_{2} \mathrm{Cu}_{3} \mathrm{O}_{7-x}$ & \\
\hline Surface resistivity & & $<$ copper at $35 \mathrm{GHz}$ & \\
\hline
\end{tabular}




\section{Summary}

Garnet substrates are viable substrates for growing microwave quality HTSC films. The film orientation and properties can be easily tailored by proper choice of the substrate orientation and some matched buffer layers. Other garnet materials with $\mathrm{Gd}$ substituted by other rare earths like $\mathrm{Y}, \mathrm{Lu}, \mathrm{Yb}, \mathrm{Tm}, \mathrm{Dy}, \mathrm{Nd}, \mathrm{Er}, \mathrm{Pr}$, $\mathrm{Sm}, \mathrm{Eu}$ etc. in $\mathrm{Gd}_{3} \mathrm{Ga}_{5} \mathrm{O}_{12}$ could be other possible good substrates for further investigations.

\section{References}

[1] R.W. Simon, C.E. Platt, A.E. Lee, K.P. Daly, M.S. Wire, J.W. Luine, M. Urbanik, Appl. Phys. Lett. 53, 2677 (1988).

[2] S. Miyazawa, Appl. Phys. Lett. 55, 2230 (1989); Y. Tazoh, S. Miyazawa, Appl. Phys. Lett. 62, 408 (1993).

[3] G. Koren, A. Gupta, E.A. Geiss, A. Segmuller, R.B. Laibowitzm, Appl. Phys. Lett. 54, 1054 (1989).

[4] R. Ramesh, A. Inam, W.A. Bonner, P. England, B.J. Wilkens, B.J. Meagher, L. Nazar, X.D. Wu, M.S. Hegde, C.C. Chang, T. Venkateshan, Appl. Phys. Lett. 55, 1138 (1989).

[5] H. Asano, S. Kudo, O. Michikami, M. Satlh, T. Konaka, Jpn. J. Appl. Phys. 29, L1425 (1990).

[6] H.M. O'Bryan, P.K. Gallagher, G.W. Berkstresser, C.D. Brandle, J. Mater. Res. 5, $183(1990)$.

[7] M. Berkowski, A. Pajączkowska, P. Gierlowski, W. Kula, R. Sobolewski, S.I. Lewandowski, B.P. Gorshunov, D.B. Lyudmirski, O.I. Sirotinski, P.A. Saltykov, H. Soltner, U. Poppe, C. Buchai, A. Lubig, Appl. Phys. Lett. 37, 632 (1990); R. Sobolewski, P. Gierlowski, W. Kula, S. Zarembinski, S.J. Lewandowski, M. Berkowski, A. Pajaczkowska, B.P. Gorschunov, D.B. Ludmirski, I.O. Sirotinski, IEEE Trans. Magn. 27, 876 (1991); S. Hontsu, J. Ishi, T. Kawai, S. Kawai, Appl. Phys. Lett. 59, 2886 (1991).

[8] P. Mukhopadhyay, J. Supercond. Sci. Technol. 4, 664 (1991); P. Mukhopadhyay, S. Gorwadkar, S.B. Ogale, R.D. Vispute, Solid State Commun. 77, 217 (1991).

[9] P. Mukhopadhyay, J. Supercond. Sci. Technol. 7, 298 (1994).

[10] P. Mukhopadhyay, J. Appl. Supercond. 1, 1961 (1993).

[11] N.P. Bansal, R.N. Simon, Appl. Phys. Lett. 53, 603 (1988).

[12] S.W. Chan, M. Chopra, C. Chi, T. Frey, C.C. Tsuei, Appl. Phys. Lett. 63, 2964 (1993).

[13] N. Kubota, Y. Shiohara, S. Tanaka, J. Mater. Res. 9, 1104 (1994).

[14] S.C. Tidrow, A. Tauber, W.D. Wilber, M.A. Bates, D.M. Potrepka, J.I. Budnic, J. Wu, S.B. Robie, R. Ortega, private communication. 